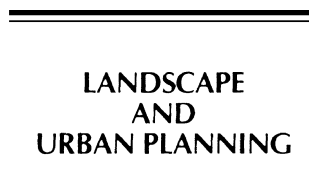

Landscape and Urban Planning 52 (2000) 21-32

www.elsevier.com/locate/landurbplan

\title{
GIS-based information flow in a land-use zoning review process ${ }^{\text {ts }}$
}

\author{
Feng-Tyan Lin ${ }^{*}, 1$ \\ Graduate Institute of Building and Planning, National Taiwan University, Taipei, Taiwan, ROC
}

Received 11 January 1999; received in revised form 24 May 2000; accepted 14 July 2000

\begin{abstract}
This work describes a geographical information system (GIS)-based information flow for a land-use zoning review process. GIS technology is employed not only to edit and display maps as conventional GIS applications, but also to enhance work quality. These enhancements include an exploration of hidden information, the production of tentative zoning maps, recognizing potentially problematic areas, conducting crucial site investigations, facilitating informative public hearing, and presenting potential policies. In the case of the Yang-Ming-Shan (YMS) National Park, Taiwan, a GIS-based information flow is employed to assist in the land-use zoning review process. This GIS-based information system reveals several features including: (1) a new, more complicated and effective information flow; (2) close coordination of computing and noncomputing sub-processes; (3) prior identification of over and under-regulated areas to avoid potential appeals and conflicts; (4) economical and effective site investigations, and (5) potential policies established for both private and public land. The case of the YMS National Park is encouraging. We believe that the application of a GIS-based information flow is beneficial to both the zoning plan production and the review process. C) 2000 Elsevier Science B.V. All rights reserved.
\end{abstract}

Keywords: Geographical information systems; Land-use zoning; Information flow

\section{Introduction}

Zoning plans, which consist of textual documents, alphanumerical tables, and graphical maps have been employed in the management of appropriate land uses in both urban and rural areas for quite some time (Keeble, 1969; Chapin and Kaiser, 1979; Last, 1995;

\footnotetext{
$\lesssim$ This research is originated from a project sponsored by the Yang-Ming-Shan National Park Headquarters, Taiwan, ROC. Part of preliminary results of GIS analyses are reported by Lan (1998).

*Tel.: +886-2-23638711; fax: +886-2-23659197.

E-mail address: ftlin@ccms.ntu.edu.tw (F.-T. Lin).

${ }^{1}$ Also with (1) the Department of Civil Engineering, National Taiwan University, Taiwan; (2) the Institute of Information Science, Academic Sinica, Taiwan.
}

van der Vlist, 1998). Zone planning, a process to produce zoning plans, involves many fields, including design art, engineering, and the sciences (Blunden, 1971; Catanese, 1972; Sol et al., 1995; Alexander, 1998). In the scientific field, paradigms in planning theory have evolved from the mathematical models of the 1950s to the planning support systems (PSS) of the 1990s. In particular, geographical information systems (GIS) technology is an essential feature of modern PSS studies (Batty, 1995; Hopkins, 1999; Kammeier, 1999).

Although, GIS technology has been recently applied to numerous fields, there are relatively few applications regarding the land-use planning process (Budić, 1998; Gordon, 1994; Peccol et al., 1996). 
Furthermore, most GIS research on land-use planning relates to the establishment of databases, the expansion of mathematical models to incorporate the capabilities of spatial analyses, (including overlaying, buffering, networking, etc.) and investigating typical "What-if" questions (Landis and Zhang, 1998; Senes and Toccolini, 1998; Kammeier, 1999).

Batty (1995) presented a conceptual diagram for a complete PSS that consisted of computing and noncomputing processes. He contended that noncomputing processes, such as political activities, are substantially related to computing processes supported by both mathematical models and information systems. Batty recommended that both these computing processes be considered in PSS, and effective interfaces for these processes constructed. A study by Kammeier (1999) proposed a partial PSS for supporting stakeholder analysis, SWOT $^{2}$ analysis, and the monitoring and evaluation of strategic planning. We believe that the entire information flow associated with zone planning must be reworked when new information technologies, such as GIS, are developed. By employing new information technology, planners can reveal hidden information, analyze spatial relationship, propose tentative zoning maps, identify problematic areas, and recommend possible computational policy solutions. Thus, noncomputing political processes, including public hearing and committee decision-making, can be both informative and effective.

This study recommends a GIS-based information flow system as an effective tool for analyzing the landuse zoning review process. The case of the YangMing-Shan (YMS) National Park, Taiwan, illustrates how: (1) useful information can be derived from base maps; (2) tentative zoning maps can be computationally produced, and (3) possible policies can be recommended through a cross-referencing of different information.

\section{GIS-based information flow}

Zoning maps are essential components of zoning plans. Many zoning plans and maps continue to be

\footnotetext{
${ }^{2}$ SWOT is the abbreviation of strengths, weaknesses, opportunities, and threats.
}

produced and reviewed manually. The expected potential of GIS technology in the improvement of the quality of zoning map production and review is well known. In the past, a majority of the work and research in this field focused on how to produce digital maps, minimize errors, deal with uncertainty, perform spatial analyses, formulate models for decision support systems, access very large databases via the internet, and visualize data by either employing a three-dimensional method or as a virtual reality. Nevertheless, information flow is another crucial, yet largely ignored, issue when GIS technology has been introduced into the zoning planning and reviewing process. By employing GIS technology, a plethora of useful information can be derived from the preliminary data, and an elaborate and re-organized information flow can be effectively practiced to significantly improve work quality. Figs. 1 and 2 illustrate the manual and GIS-based information flows, respectively.

Fig. 1 depicts a relatively simple manual information flow. Before revising zoning maps (in plans), planning agencies may conduct the necessary investigations on sites where both the appeals and public opinions refer. Normally, both topographical and current zoning maps are employed to this process. Current zoning criteria may be modified according to the appeals, public opinions, and the results of site investigations. Finally, current zoning maps (in plans) are reviewed and then revised by applying a comprehensive and noncomputing approach.

GIS-based information flow (as shown in Fig. 2) takes advantage of the GIS technology by fully utilizing the spatial information and extensively interacting with the noncomputing information, including landholders' appeals, public hearing, committee opinions, and site investigations.

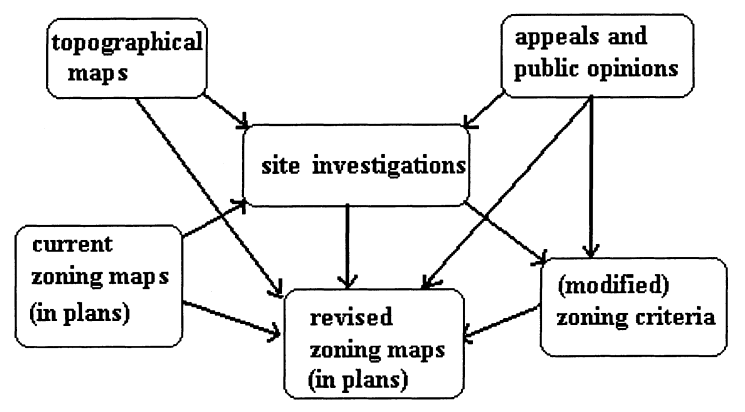

Fig. 1. Information flow in manual zoning review processes. 


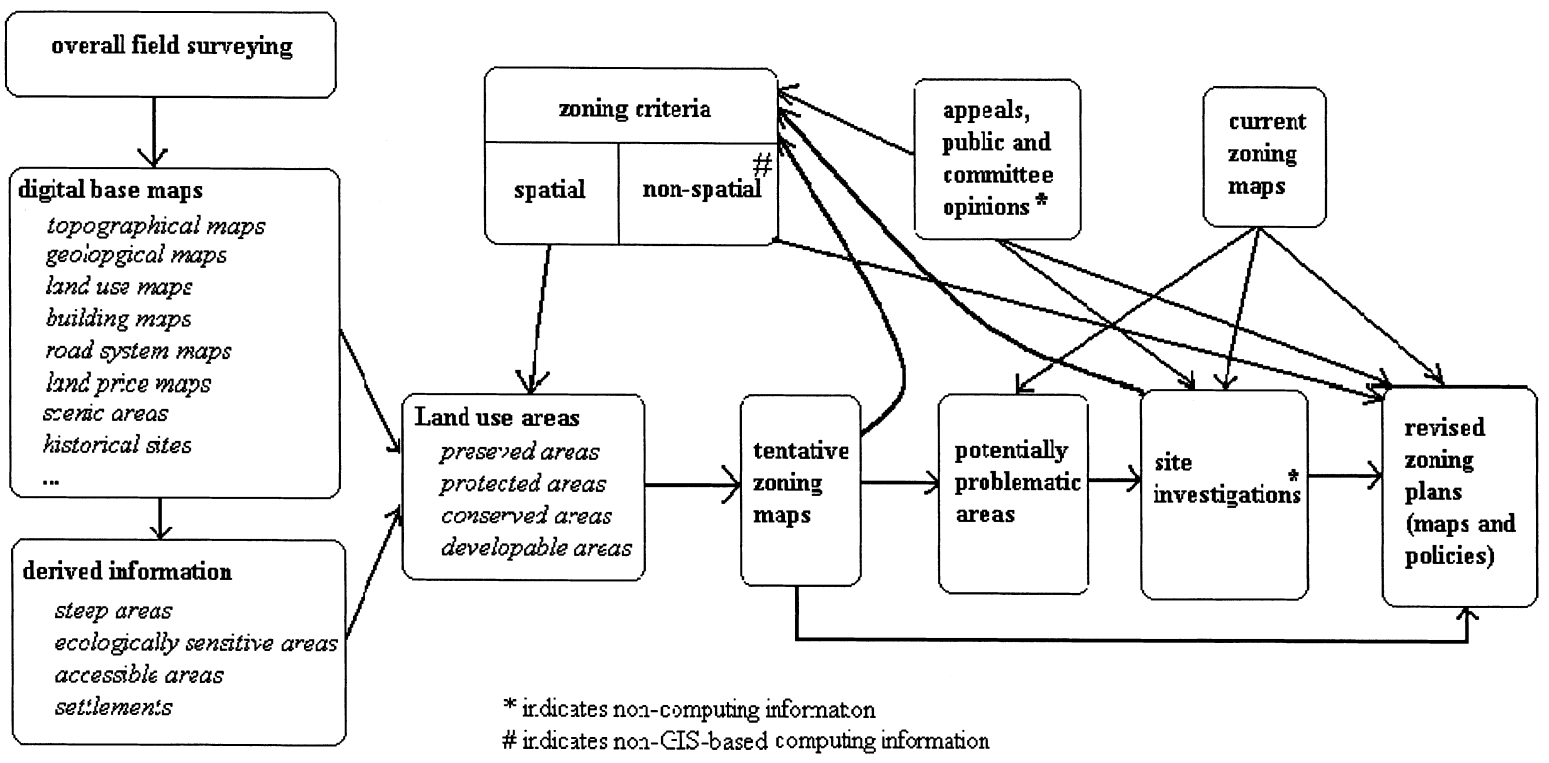

Fig. 2. GIS-based informational flow in zoning review process.

Initially, overall field surveys and data collections are conducted to prepare a set of base maps, including topographical maps, geological maps, land-use maps, road system maps, building maps, land price maps, scenic area maps, and historical site maps. The relevant information, including the steep areas, ecologically sensitive areas, accessible areas, and scales of settlement clusters, is then derived from the digital base maps by employing different spatial analysis functions in GIS.

Conventionally, zoning criteria are stated in terms of "natural language". Usually, the planning agencies and committee members scrutinize the criteria and informally arrive at their decision. Fig. 1 depicts how zoning criteria are applied in the production of the revised final zoning map. In contrast to this method, a GIS-based zoning practice applies the spatial criteria to geo-referenced maps at a very early stage. Preserved, protected, conserved, and developable areas are identified and tentative zoning maps are proposed. Nonspatial criteria will be considered in the later section of this paper when the data regarding the noncomputing information, comprehensive decisions, judgements upon individual appeals, and site investigation is included.

Conflicts arise between the criteria drawn from diverse public opinions, appeals, and viewpoints, including environmental protection, economic development, recreation activities, and residential requirements. Namely, in a majority of cases, planners encounter multiple-criteria and multiple-objective problems for which feasible, instead of optimal, solutions are sought. Nijkamp (1984) has identified several classes of methods to solve these problems. This study recommended an interactive evaluation procedure in cases where extensive information exchanges between the planners and decision-makers. This procedure is especially helpful in situations where the decision committee could not explicitly specify its preferences or weights regarding evaluation criteria. Harris (1999) also recognized that sketch planning is beneficial in the transformation of public hearing from confrontation to collaboration. The public is capable of accessing the information, models, maps, plans, and computing methods available to the planners. By employing this method, decisions are coordinated and innovations are tested. Therefore, a substantial increase in the quality of work occurs.

In terms of GIS-based planning, issues concerning adaptive criteria and interactive information processing are crucial to flexible and dynamic sketch planning. Fig. 2 depicts the different standards and thresholds associated with the spatial criteria. It illustrates how the spatial criteria can be intensively tested 
to explore its implication on zoning maps by utilizing the powerful capability of spatial computations. Public hearing can be proceeded upon tentative zoning maps, and numerous alternatives can be explored and considered at an early stage. By employing this method, the planning process will be more effective, and zoning criteria will be more practical.

Site investigations would be conducted if further information for legislating zoning decisions is required. In contrast to field surveys conducted in the very early stages, site investigations focus on relatively small areas or individual sites to obtain a deeper understanding of the area under consideration.

Potentially problematic areas are located by recognizing the differences in an overlay of the current and tentative zoning maps. Tentative zoning maps are logically and mechanically generated by performing systematic spatial analysis functions, such as overlaying and buffering, on base maps according to spatial zoning criteria. The differences between tentative and current maps can be the result of insufficient local information on the base maps, or inconsistencies between the land-use, topographical information, current zoning maps and zoning criteria. Site investigations complete insufficient information and explore any inconsistencies so that the revised zoning plan can present a more solid, feasible, and practical representation of the area under consideration.

\section{A case study: the YMS National Park zoning plan}

The YMS National Park, is located in northern Taiwan near the Taipei metropolitan area (population exceeds 8000000 people). The park covers a total area of 11455 ha with elevations ranging between 200 and $1120 \mathrm{~m}$ above sea level. The geographical situation of the YMS National Park is depicted in Fig. 3 and its road systems and buildings are illustrated in Fig. 4. Due to the economic growth and increasing recreation demands of the Taipei metropolitan area, the park is experiencing serious conflicts between natural resource protection and land development.

Fig. 5 illustrates four types of zones in the YMS National Park, which are the ecological protection, special scenery, recreation, and developable zones. The developable zone is divided into four classes, which allow for the different degrees of construction and service activities. The current zoning map is

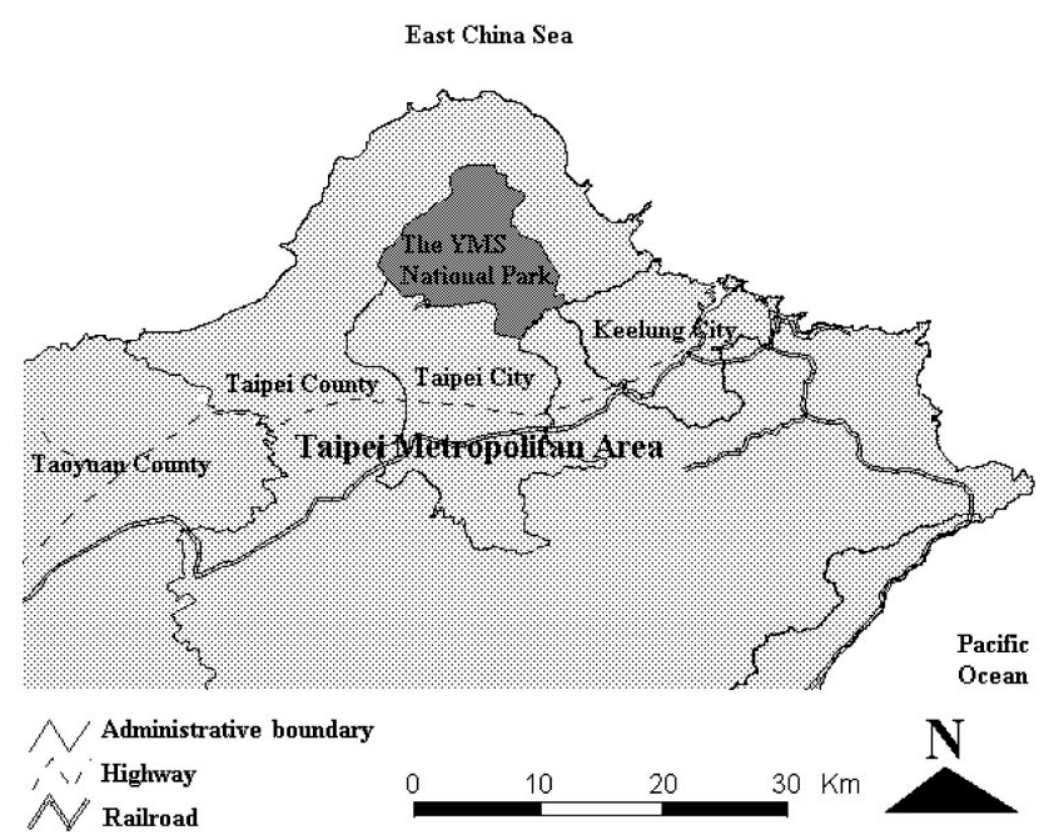

Fig. 3. Location of the YMS National Park (The YMS National Park Headquarters, Taiwan, 1999). 


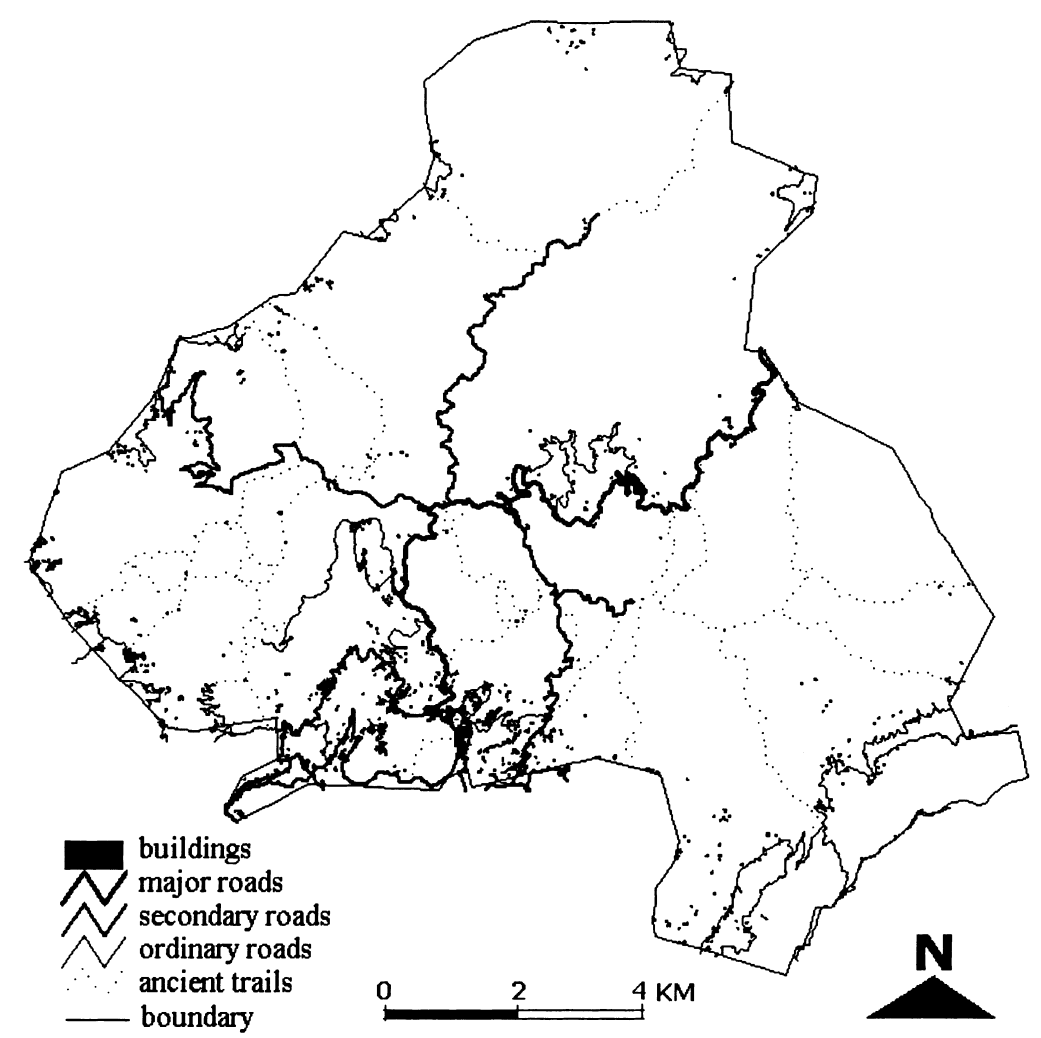

Fig. 4. Road systems and buildings (The YMS National Park Headquarters, Taiwan, 1999).

depicted in Fig. 6. Classes 1 and 2 of developable zone are too small to be represented.

The current zoning plan was initially devised in 1988 and revised a total of four times prior to 1994.
Although, diverse criteria, concerning topography, geology, transportation, existing settlement clusters, and park recreation needs, were represented in the plans, it was difficult for the planners to manually

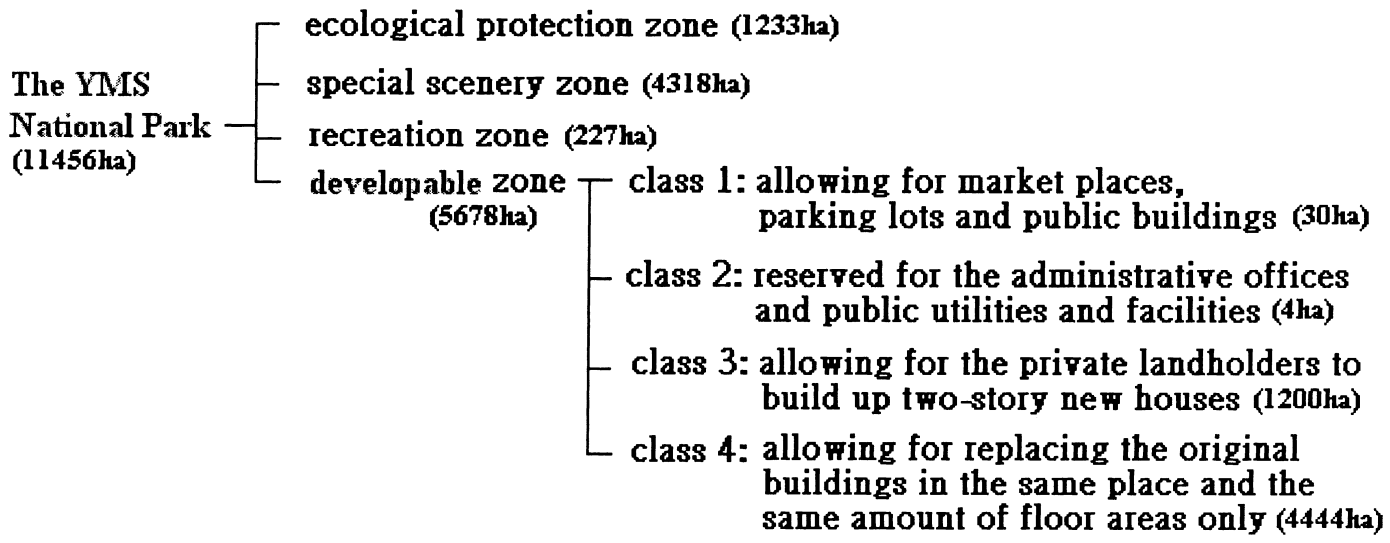

Fig. 5. Zoning categories of the YMS National Park. 


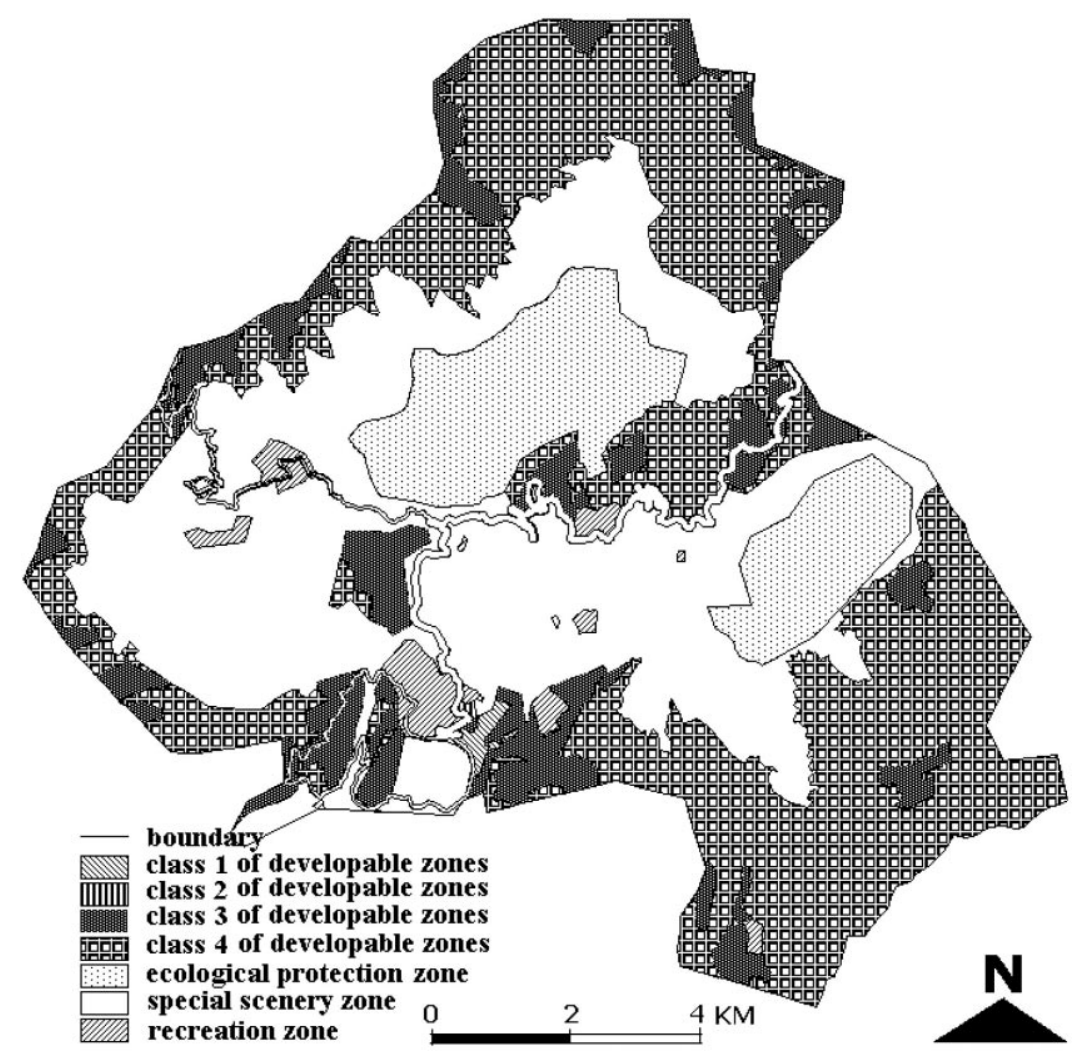

Fig. 6. The current zoning map (The YMS National Park Headquarters, Taiwan, 1999).

depict the above criteria on paper maps. As a result, many inconsistencies were apparent between the claimed criteria and zoning maps. These inconsistencies stimulated a plethora of complaints and appeals from landholders, and increased the administrative burden of park management.

Furthermore, class 3 of the developable zone allows for private landholders to construct new two-story houses, whereas class 4 allows for the replacement of the original buildings on the same location with the same amount of floor space. Accordingly, landholders in class 4 areas appeal to the planning agency to rezone them to a class 3 so that they may expand or construct new buildings.

To manage the inconsistencies and appeals, the planning agency uses PC Arc/Info (ESRI Inc., Redlands, CA.), a GIS software, to assist in the zoning review. This article is limited to a discussion of the issues associated with classes 3 and 4 of developable zones.

\section{Spatial criteria and derived information}

\subsection{The relationship}

Ideally, zoning maps should coincide with a certain criteria supported by the appropriate data sets. Therefore, it is common practice to produce zoning maps by overlaying diverse data sets according to a certain criteria whenever GIS is applicable. Obviously, different sets of criteria and data will produce different zoning maps. However, in practice, the data sets that are available for a certain project during a certain period are almost always incomplete. Therefore, the task of choosing the appropriate criteria becomes an essential component of any project.

In the current zoning plan of the YMS National Park, spatial criteria consists of three constraints and two factors relating to the assignment of an area in the developable zones to a class 3 or 4 status. An area is given class 4 status if it meets the following three 
constraints: (1) it is highly geologically unstable; (2) the degree of its slope is more than $30^{\circ}$, and (3) it is located within a water quality and volume protection area, (i.e. the land is deemed a precious water resource, such as a reservoir or a geological water source. Conversely, two factors allow for: (1) existing settlement clusters, and (2) accessible areas from major, secondary, or ordinary roads to be considered (not in every case) for class 3 status.

When the zoning plan was initially produced in 1988, these five criteria were informally treated as guidelines due to the following reasons:

- At that time, the planners only possessed a 1:5000 scale topographical paper map. Other spatial data, including geological stability, was insufficient to support the information demanded by the criteria.

- Although, elevation contours were plotted on the paper map, it was impractical for the planners to manually calculate the degrees of slopes for the whole national park given the time constraints.

- Concepts of accessibility and settlement clusters in the two soft criteria were very vague and undefined. Hence, these two criteria became very subjective.

Fortunately, these difficulties are currently eased by the addition of new data sets conducted by the YMS National Park Headquarters and recently developed GIS technology. A study recognizing the geologically sensitive areas was finished in 1989. Basic maps, including the zoning map, cadastral maps, and water protection area maps, were digitized and a geographical information system was established in the early 1990s. Furthermore, a new 1:1000 scale topographical map was completed in 1997. The new topographical map was also released in a GIS format.

By employing the GIS technology, the appropriateness of accessibility and settlement clusters on the current zoning maps were examined, and vegetationsensitive maps can be also derived from topographical maps. The following three subsections describe how GIS techniques were used to explore the accessibility, settlement clusters, and vegetation-sensitive areas.

\subsection{Accessibility}

The YMS zoning plan of 1988 vaguely recommended that the areas of class 3 in the developable zones should be accessible. There were no further statements regarding a measurement of the degree of accessibility. Fortunately, the accessible areas can be currently partially identified by using GIS technology.

According to the daily experiences of park managers, a conjecture, (namely that accessible distances from roads to developed sites are generally within $300 \mathrm{~m}$ ), is proposed. To test this conjecture and recognize the potentially inaccessible areas, buffered areas (of $300 \mathrm{~m}$ as a threshold from the road systems), were produced and overlaid to areas of class 3 . It was discovered that $28 \%$ of class 3 on the current zoning map were not located within the conjectured accessible distance (Fig. 7). This result implies that site investigations should be conducted on the areas beyond the conjectured distance to ascertain if: (1) they are mis-assigned to class 3 on the current zoning map, and (2) there is missing information, such as unrecorded roads or trails, to be added.

\subsection{Defining settlement clusters}

To satisfy the demands of an increasing population, residents in areas of class 4 of the developable zones are appealing to the planners to re-assign their zones to

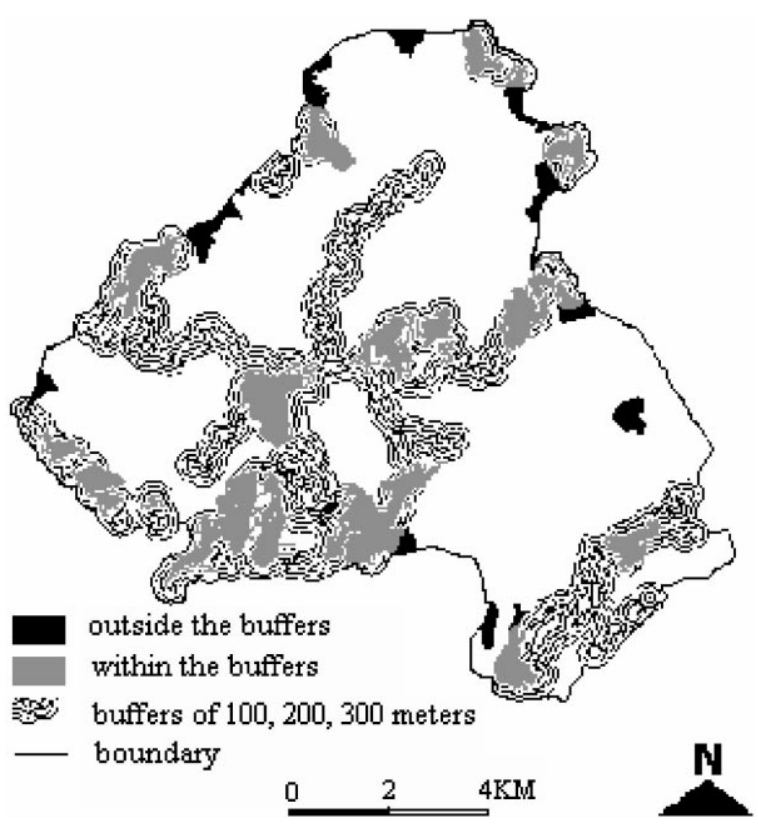

Fig. 7. Areas of class 3 overlaid by buffered areas of $300 \mathrm{~m}$ from roads. 
class 3 in order to obtain permits to construct new buildings. From the viewpoint of the planning agency, new buildings have to be restricted within the existing settlement clusters so that numerous supply lines and sewers can be managed to minimize environmental impacts. However, there is no exact definition to determine what settlement clusters are comprised of in the YMS National Park, even though the current zoning plan includes a settlement cluster map. Thus, a key issue in the park is the identification of settlement clusters.

Among the diverse considerations from geographical, cultural, social, and historical perspectives, the distributions of the distances among buildings and the sizes of clustered built areas depicted on the current settlement cluster map are important references for the planners in order for a just ruling. To calculate these distributions, GIS techniques are employed.

First, the centroids of buildings are identified. Analyses of the triangulated irregular network (TIN) are then performed upon the building centroids for each settlement cluster. Fig. 8 depicts a component of these analyses. The distribution of the building distances is illustrated in Fig. 9, which demonstrates that most buildings within a settlement cluster are $35 \mathrm{~m}$ apart. Thus, a GIS criterion is established to specify that buildings within $35 \mathrm{~m}$ of one another is a necessary conditions for the buildings to be considered as a settlement cluster.

Then the clusters within the built areas were identified. To accomplish this, each building was buffered by a measurement of $17.5 \mathrm{~m}$, (i.e. half of $35 \mathrm{~m}$ ). The

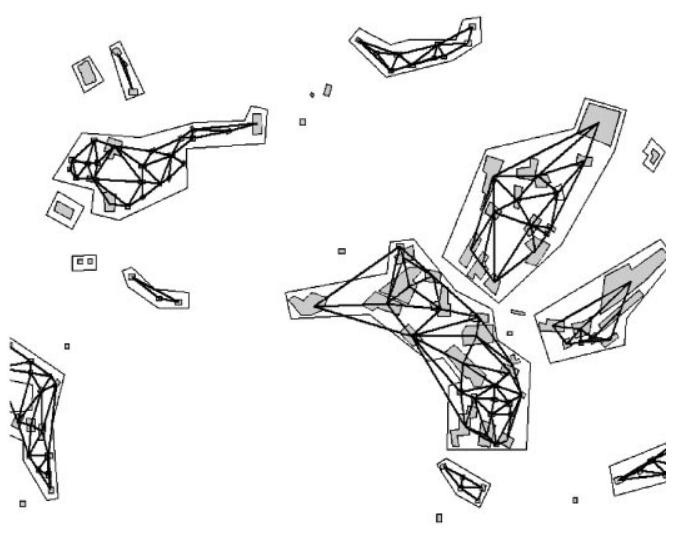

Fig. 8. Triangulated irregular network analysis of settlement clusters.

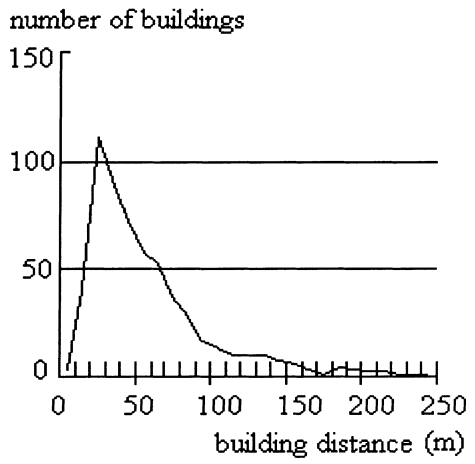

Fig. 9. Distribution of building distances.

distribution of the number of buildings in clusters, (which are defined as the connected areas of buffered buildings), was plotted in Fig. 10. Since development behaviors are discouraged in the national park, there is a tendency to confine new buildings to well established, yet limited, settlement clusters. Therefore, the larger a clustered built area, the higher possibility that it will be considered as a settlement cluster. However, it is difficult to choose the minimum size of settlement clusters. In fact, this determination is a political process in order to balance the expectations of the landholders and the planning agency. This is achieved by conducting a number of public hearing.

As a result, two thresholds, associated with $35 \mathrm{~m}$ and seven buildings, were employed to produce a tentative map of settlement clusters (Fig. 11), which depicts that there were 166 settlement clusters with $3545(78.73 \%)$ out of 4503 buildings (in the entire national park). The total area of settlement clusters is about 270 ha, and $48 \%$ of the areas with settlement clusters are currently assigned class 3 status.

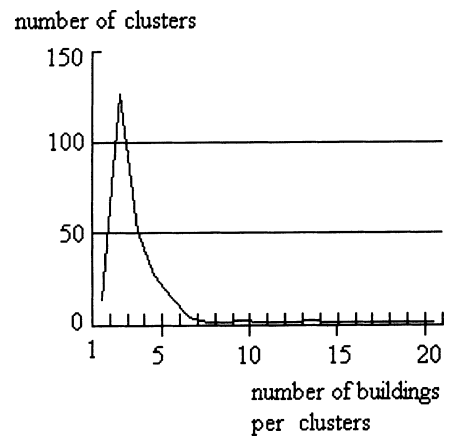

Fig. 10. Distribution of sizes of settlement clusters. 


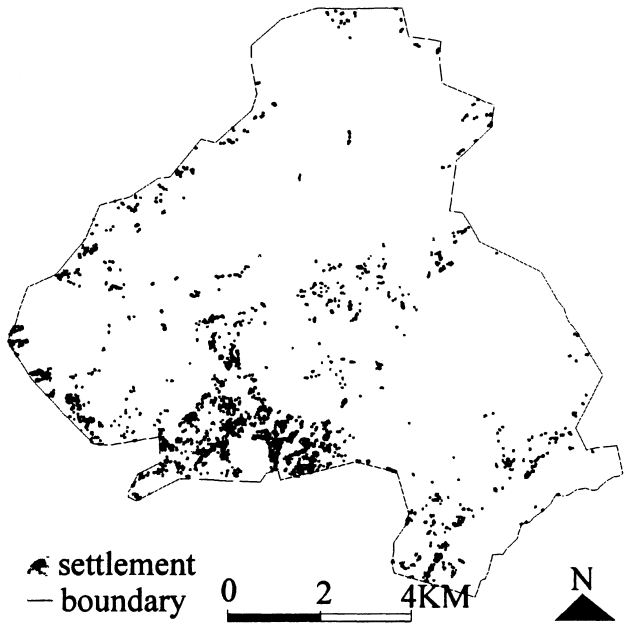

Fig. 11. A tentative map of settlement clusters.

\subsection{Vegetation-sensitive areas}

Ideally, vegetation-sensitive areas should be derived from vegetation maps. Yet, in the case of the YMS National Park, vegetation maps are unavailable when the zoning plan was under review. To remedy this shortage, several botanists have suggested that a $200 \mathrm{~m}$ buffered area in the ridges and valleys be designated as ecological sensitive areas. Accordingly, GIS techniques have been employed to derive the locations of ridges and valleys from the digital elevation data and then to compute the buffered areas.

\section{GIS-based computation}

After obtaining the digital data sets and spatial criteria, the techniques of spatial analyses in GIS are employed to: (1) construct tentative zoning maps; (2) identify the potentially problematic areas; (3) test "what-if" relations, and (4) propose possible policies for the areas of classes 3 and 4 in developable zones. As a result, the site investigations and public hearing can be effectively implemented. The information flow of the GIS-based computation is presented in Fig. 12, where the notations in the form of $A \leftarrow B$ indicates that the result (or value) of expression $B$ is assigned to the variable $\mathrm{A}$.

Classes 3 and 4 areas in the developable zones on the current zoning map were extracted and denoted as
CC3 and CC4, respectively. The union of $\mathrm{CC} 3$ and $\mathrm{CC} 4$ is denoted as the study area $\mathrm{S}$ in the YMS case. Settlement clusters, vegetation-sensitive areas, and accessible areas (denoted as S1, S4, and S5, respectively) are derived from the topographical map according to certain spatial criteria and thresholds as was previously illustrated. Conversely, other authorities independently zoned the water protection areas and geographically sensitive areas. In the YMS case, these are exogenous data and denoted as S3.

The settlement clusters $\mathrm{S} 1$ in the study area $\mathrm{S}$, calculated by $\mathrm{S} \cap \mathrm{S} 1$, was assigned an accumulative variable $\mathrm{C} 3$, which corresponded to the new areas of class 3 . The remaining areas were assigned a decreasing variable $S 2$, which was subsequently subtracted in turn by: (1) the water protection areas and geographically sensitive areas (S3); (2) the steep areas where the slopes equaled or exceeded $30^{\circ}$, and (3) the vegetation-sensitive areas (S4). Then, the accessible areas (S5) in the remained areas (S2) were added to $\mathrm{C} 3$. The study area $\mathrm{S}$ outside of $\mathrm{C} 3$ was assigned to $\mathrm{C} 4$. Thus, $\mathrm{C} 3$ and $\mathrm{C} 4$ represent a tentative zoning map. Similarly, other tentative zoning maps can be produced by establishing alternative criteria and thresholds.

Cadastral maps can be overlaid with the tentative zoning maps to obtain some insights and propose possible policies. Recognizing potentially problematic areas can be achieved by comparing the current and tentative zoning maps, (i.e. the differences between $\mathrm{C} 3, \mathrm{CC} 3, \mathrm{C} 4$ and $\mathrm{CC} 4$ ). In particular, these potentially problematic areas can be characterized as either over- or under-regulated areas. Currently, overregulated areas merit more opportunities for land development, and under-regulated areas require further restrictions. Thus, the solutions to "what-if" questions can be tested by establishing different spatial criteria and thresholds, and examining the corresponding tentative zoning maps and potential problematic areas.

Based on the preliminary analyses, these potentially problematic areas require detailed site investigations, careful examinations, and intensive discussions during public hearing. The results of public hearing and site investigations can then be inputted to reset the spatial criteria and thresholds. Theoretically, new cycles of producing or revising tentative zoning maps can be indefinitely evoked in this way. These cycles will eventually arrive at a new zoning map. 


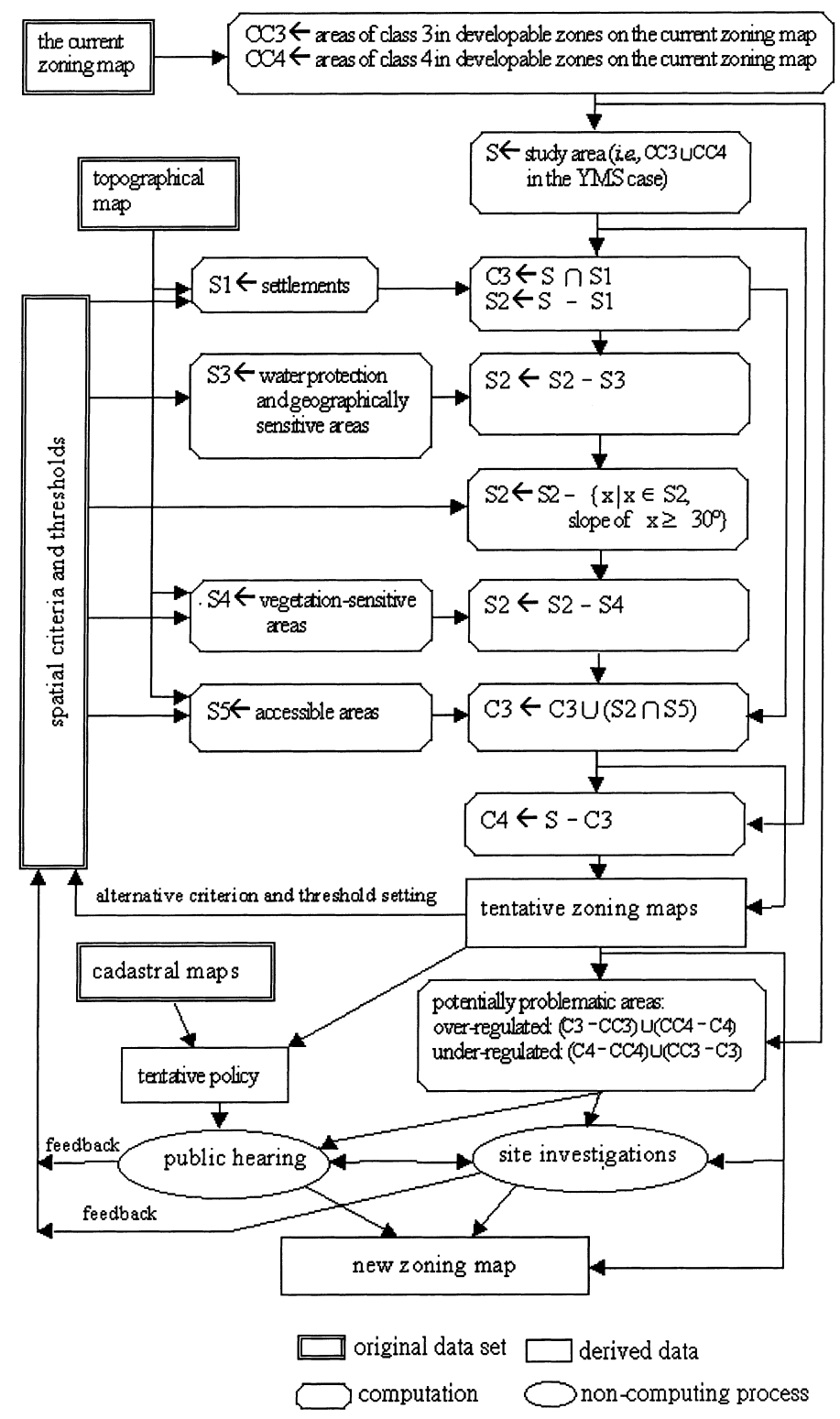

Fig. 12. Information flow in GIS-based computation.

For example, a tentative map based on the criteria and thresholds mentioned in the previous section was compared to the current zoning map in Table 1. The coincident area (as represented on the diagonal) measures 4344 ha $(79.69 \%)$. The over-regulated area (Fig. 13) measures 48 ha $(0.89 \%)$, while the underregulated area (Fig. 14) measures 1059 ha (19.42\%). The results reveal that the current zoning plan is not as effective as was previously claimed, and suggests that the over-regulated areas on the tentative map require further site investigation to determine if they can be redesignated as a class 3 area.

Furthermore, taking the land ownership information into account can inspire feasible policies. For example, by overlaying the cadastral maps on the underregulated areas, the planning agency discovers that 
Table 1

Comparison of land uses by original and revised criteria (ha)

\begin{tabular}{lrrr}
\hline & New class 3 & New class 4 & Total \\
\hline Original class 3 & $139(2.55 \%)$ & $1059(19.43 \%)$ & $1198(21.98 \%)$ \\
Original class 4 & $48(0.88 \%)$ & $4205(77.14 \%)$ & $4253(78.02 \%)$ \\
Total & $187(3.43 \%)$ & $5264(96.57 \%)$ & $5451(100.00 \%)$ \\
\hline
\end{tabular}

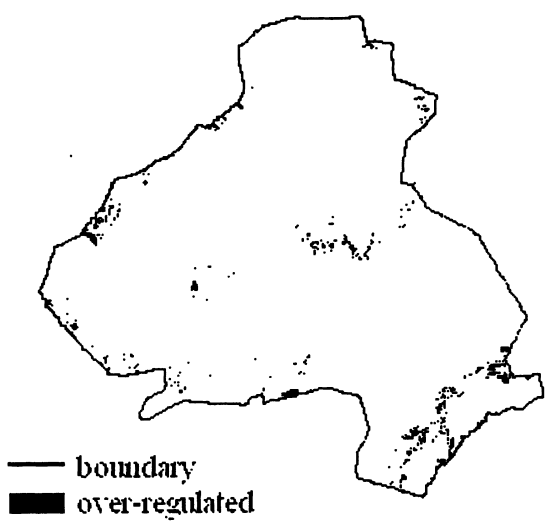

areni:

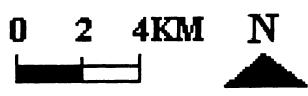

Fig. 13. Over-regulated areas.
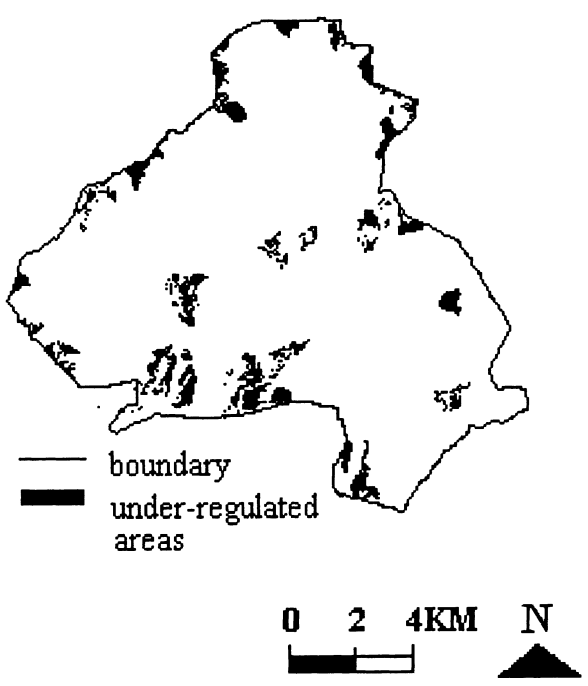

Fig. 14. Under-regulated areas. there are 283 ha $(26.72 \%)$ of public lands, 605 ha $(57.13 \%)$ of private lands, and 171 ha $(16.15 \%)$ of data unknown or unavailable. The planning agency then establishes different policies for different landholders.

Public lands, owned by the Bureau of Forest Management of the Taiwan Provincial Government, could be directly re-designated as class 4 through the administrative authority. Other feasible policies, such as the land purchase or development right transfer of private lands, have to receive further study and evaluation.

\section{Conclusion}

A GIS-based land-use zoning review process is described in this article. It demonstrates a feasible approach to integrate computing and noncomputing processes residing in the zone planning. The GISbased computational flow implies a possible implementation of planning support systems in the future.

This work also demonstrates how spatial criteria can be specified in an operational way. Particularly, concepts of accessibility, settlement clusters, and vegetation-sensitive areas are clarified in terms of GIS computation. However, the GIS-based process may be modified or improved if additional databases or new technologies are available.

Furthermore, the case of the YMS National Park illustrated that GIS technology helped the planning agency a lot. By adjusting the work flow, providing sufficient information and analyzing potential problems in a systematic way, noncomputing processes, including field investigations, public hearing, and zone plan review, proceeded informatively and effectively. This experience is encouraging. It is expected that the GIS-based process can be further generalized so that not only other national parks but also general city planning can take advantage of GIS technology. 


\section{References}

Alexander, E.R., 1998. Doing the 'impossible': notes for a general theory of planning. Environ. Plan. B: Plan. Design 25, 667-680.

Batty, M., 1995. Planning support systems and the new logic of computation. Reg. Develop. Dialogue 16 (1), 1-17.

Blunden, W.R., 1971.The Land-use/Transport System: Analysis and Synthesis. Pergamon press, New York.

Budić, Z.D., 1998. The impact of GIS technology. Environ. Plan. B: Plan. Design 25, 681-692.

Catanese, A.J., 1972. Scientific Methods of Urban Analysis, University of Illinois Press, Chicago.

Chapin Jr., F.S., Kaiser, E.J., 1979. Urban Land use Planning, 2nd Edition. University of Illinois Press, Chicago.

Gordon Jr., W.R., 1994. A role for comprehensive planning, geographical information system (GIS) technologies and program evaluation in aquatic habitat development. Bull. Mar. Sci. 55 (2/3), 995-1013.

Harris, B., 1999. Computing in planning: professional and institutional requirements. Environ. Plan. B: Plan. Design 26, 321-331.

Hopkins, L.D., 1999. Structure of a planning support system for urban development. Environ. Plan. B: Plan. Design 26, $333-$ 343.

Kammeier, H.D., 1999. New tools for spatial analysis and planning as components of an incremental planning-support system. Environ. Plan. B: Plan. Design 26, 365-380.

Keeble, L., 1969. Principles and Practice of Town and County Planning, 4th Edition. The Estates Gazette Limited, London.

Lan, K.B., 1998. GIS-Assist Zoning Criteria Setting - A Case Study on the YMS National Park, Master thesis (in Chinese), The Graduate Institute of Building and Planning, National Taiwan University, Taipei, Taiwan.

Landis, J., Zhang, M., 1998. The second generation of the California urban futures model, part 1: Model logic and theory. Environ. Plan. B: Plan. Design 25, 657-666.
Last, D.G., 1995. Incremental land-use decision making displayed by county zoning committees. J. Soil Water Conserv. 50 (1), 21-24.

Nijkamp, P., 1984. Information systems: a general introduction. In: Nijkamp, P., Rietveld, P. (Eds.), Information Systems for Integrated Regional Planning. Elsevier, New York, pp. 3-33.

Peccol, E., Bird, A.C., Brewer, T.R., 1996. GIS as a tool for assessing the influence of country side designations and planning policies on landscape change. J. Environ. Manage. 47, 355-367.

Senes, G., Toccolini, A., 1998. Sustainable land use planning in protected rural areas in Italy. Landsc. Urban Plan. 41, 107117.

Sol, V.M., Lammers, P.E.M., Aiking, H., de Boer, J., Feenstra, J.F., 1995. Integrated environmental index for application in landuse zoning. Environ. Manage. 19 (3), 457-467.

van der Vlist, M.J., 1998. Land use planning in the Netherlands finding a balance between rural development and protection of the environment. Landsc. Urban Plan. 41, 135-144.

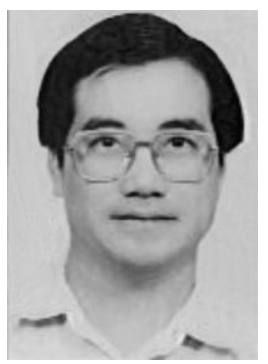

Dr. Feng-Tyan Lin, born in 1956, is an associate professor and the director of the Graduate Institute of Building and Planning, National Taiwan University, Taiwan. He received a degree of Bachelor of Engineering on urban planning from National Cheng Kung University, Taiwan, and degrees of master and $\mathrm{PhD}$ on computer science from Northwestern University, USA His main interests lie in computer aided urban planning and architecture design systems. He has many experiences in configuring geographical information systems for local governments. He believes that logic is a powerful tool to analyze planning and design systems. 